\title{
PRESUPUESTOS ANTROPOLÓGICOS DEL DESARROLLO HUMANO INTEGRAL COMO PROYECTO DE VIDA ÉTICA A LA LUZ DE LA ENCÍCLICA CARITAS IN VERITATE
}

Ángel Gómez Navarro*

\begin{abstract}
RESUMEN
El desarrollo humano integral es el desafí ético fundamental, que el hombre hodierno debe asumir como auténtico proyecto de vida ética por el que busque alcanzar responsablemente la unidad y el sentido de su existencia. El presente texto reflexiona sobre las condiciones de posibilidad de este proyecto dinámico de autorrealización integral, tales como la vocación de apertura a lo trascendente, la relación dialógica o intersubjetiva, la libertad de autodeterminación, el discernimiento ético y el compromiso responsable.
\end{abstract}

PALABRAS CLAVE:

Vocación, autorrealización, ética, libertad, discernimiento.

\section{ANTHROPOLOGICAL ASSUMPTIONS ON THE COMPREHENSIVE HUMAN DEVELOPMENT AS AN ETHICAL LIFE PROJECT UNDER THE LIGHT OF THE CARITAS IN VERITATE ENCYCLICAL}

\begin{abstract}
To achieve comprehensive human development is the fundamental ethical challenge that the contemporary man must undertake as true ethical life project to responsibly seek unity and the sense of existence. This paper explores the likelihood conditions of this comprehensive selfachievement dynamic project, such as the willingness to be open to what is transcendent, the dialogic or intersubjective relationship, the freedom of self-determination, the ethical discernment and the responsible commitment.
\end{abstract}

\section{KEY WORDS:}

Vocation, Self-realization, ethics, freedom, discernment.

\footnotetext{
* Doctor en Teología por la Pontificia Universidad Gregoriana de Roma. Egresado de la Maestría en Antropología de la Pontificia Universidad Católica del Perú. Catedrático Principal de la Universidad Femenina del Sagrado Corazón y Jefe del Departamento de Filosofía y Teología de la Facultad de Psicología y Humanidades de la misma Universidad.
} 


\section{INTRODUCCIÓN}

I os complejos problemas éticos que Lafectan a nuestras sociedades democráticas, cuyas consecuencias se globalizan de manera rápida y confusa, como la acentuación de las desigualdades socioeconómicas y culturales, la contaminación ambiental, la corrupción política y la manipulación de la vida humana, nos instan a reconocer que tamaños problemas, entre otros más, se agudizan principalmente por la ausencia de un auténtico proyecto de vida ética y un subjetivismo axiológico enraizado en el individuo, sumergido en una profunda crisis valorativa; lo que a su vez manifiesta una grave reducción antropológica porque desvirtúa seriamente la unidad y el sentido trascendente de la existencia humana.

En consecuencia, el desafío hodierno no sólo consiste en la elaboración inmediata y consensuada de planes políticos estratégicos, flujo inteligente de capitales, acceso a la tecnología de última generación o la adquisición de habilidades técnicas, ejecutivas o gerenciales, sino que exige un profundo re-descubrimiento de lo que significa e implica la única vocación excelsa del hombre, como es su propia autorrealización integral, por el que proyecte su propia existencia dinámica con un sentido de libertad responsable y un amor inteligente capaz de establecer adecuadas y creativas relaciones con Dios, con los otros, con las cosas y con las variadas formas de vida natural. En este sentido, los términos del desarrollo humano integral, que Benedicto XVI nos presenta en su encíclica Caritas in Veritate (Caridad en la
Verdad) ${ }^{1}$, tienen que ver con este proyecto de vida ética que busca el ideal de la unidad y del sentido de la vida de todo el hombre y de todos los hombres, el mismo que se activa sólo a partir de una espiritualidad de metanoia o de conversión de pensamiento, sentimiento y acción, basada en la dinámica teológica y axiológica del amor en la verdad, orientada a promover compromisos concretos de corresponsabilidad solidaria, en y desde la comunidad donde convivimos. De este modo se configura un ethos que va más allá de los hábitos personales y de las prácticas sociales, buscando un permanente diálogo intersubjetivo sobre las valoraciones morales de nuestras complejas relaciones interpersonales que se generan, tanto en la vida pública como en la vida privada, promoviendo de este modo criterios éticos válidos para una vida digna de ser vivida.

Pero, ¿Cuáles son los presupuestos fundamentales o las condiciones de posibilidad de este desarrollo humano integral, visto como un proyecto de vida ética para los hombres y las mujeres de hoy? Para responder a esta pregunta nos proponemos la tarea de sacar a la luz aquellos significados -contenidos en la encíclica Caritas in Veritate de Benedicto XVI- como la vocación trascendente del hombre, la relación dialógica o intersubjetiva, la libertad, el discernimiento ético y el compromiso responsable, buscando poner de manifiesto lo que tienen de luminoso y esperanzador para la construcción efectiva y dinámica de nuestra propia autorrealización integral, y así, recorrer junto a otros, el camino histórico de un verdadero humanismo crítico y trascendente.

1 Las reflexiones de la presente encíclica (2009), tienen como referente teórico específico el magisterio pontificio del Papa Pablo VI, especialmente la encíclica social Populorum progressio (1967), dedicada al desarrollo de los pueblos, y, más en general, la doctrina social de la Iglesia, que hunden sus raíces últimas en la Tradición de la fe cristiana apostólica. La finalidad consiste en actualizar el mensaje cristiano de la Populorum progressio que, según Benedicto XVI merece ser considerada como "la Rerum novarum de la época contemporánea", que ilumina el camino de la humanidad en vías de unificación (cf. CV 8 y 10). 


\section{Vocación genuina del hombre y el sentido de la vida}

Desde una antropología filosófica reconocemos que el desarrollo humano integral es el fin natural primordial que sólo el hombre puede conocer como tal en virtud de su facultad intelectiva -la cual es capaz de anticiparse previsoramente a los actos humanos y a los acontecimientos históricos-, y al mismo tiempo, quererlo realmente por su facultad espiritual volitiva, que es la única que puede determinar libremente la realización efectiva de este desarrollo humano total, no en cuanto fin secundario sino, precisamente, en cuanto fin primordial al que deben supeditarse todos los demás fines del hombre. Este fin primordial, que al mismo tiempo es sentido por la dimensión afectiva de las motivaciones ${ }^{2}$, se caracteriza también por ser un bien moral -que la tradición filosófica llama bien honesto ${ }^{3}$ porque se ordena a la perfección gradual del hombre y a su libre autodeterminación. Pero, no se trata de la sola representación abstracta de un fin bueno, sino de un bien en sí mismo, objetivo y universal, real y concreto, histórico y trascendente, que debe ser buscado en cuanto que es capaz de darle sentido y unidad a la existencia de todo ser humano. Sin embargo, la primera dificultad surge cuando el hombre busca sólo el bien placentero y utilitario, seducido por una axiología hedonista propia de la cultura dominante, que concibe el desarrollo humano sólo en términos de consumo, tecnología y producción económica.

Este desarrollo humano debe ser integral porque concierne de manera unitaria a la totalidad de la persona humana en todas sus dimensiones constitutivas: biológica, psicológica, sociocultural, espiritual y teologal. Todas estas dimensiones deben ser cultivadas pedagógicamente, sin perder nunca de vista la dimensión teologal o trascendente, pues como defiende Benedicto XVI, el hombre no puede quedar encerrado dentro de los límites de la historia porque quedaría expuesto al riesgo del querer "tener más", renunciando gravemente a buscar su propio fin (CV 11).

Por consiguiente, todo ser humano tiene que reconocerse, desde lo más íntimo de su ser, abierto y orientado hacia su propio desarrollo integral, que va más allá de la dimensión biológico-instintiva; y hacer de ello un verdadero fin intencionado, es decir, una auténtica opción fundamental, -con motivaciones psicológicas incluidas-, por el que busque alcanzar progresivamente, dicho desarrollo, mediante la elección y ejecución de los medios (o acciones) considerados convenientes por la previa deliberación.

En virtud de esta opción, conciente y voluntaria, el hombre se elige a sí mismo

2 Con R. Yepes sostenemos que la afectividad es una 'zona intermedia' donde se unen lo sensible y lo espiritual, o sea, entre las inclinaciones o tendencias instintivas de la dimensión sensitiva y las tendencias -intelectiva y volitiva- de la dimensión espiritual del hombre. Esta afectividad es también una dimensión constitutiva del ser humano, que comprueba la unidad sustancial de alma y cuerpo, ya que en ella habitan, como potencias, los sentimientos, las motivaciones, las emociones y las pasiones. Tales sentimientos, -que no deben ser confundidos con las sensaciones-, afectan positiva o negativamente nuestra subjetividad y le confieren carácter vivencial a nuestras experiencias internas. Cf. Fundamentos de Antropología. Un ideal de la excelencia humana. EUNSA, España, 1996.

3 No debe confundirse el bien moral (o bien honesto) con el bien ontológico ya que éste es la propiedad de todos los entes en cuanto tales. Es decir, aunque todo ser es ontológicamente bueno, no necesariamente todo ser es moralmente bueno. Tampoco se le debe identificar con el bien útil o el bien placentero que más bien son fines o bienes secundarios. Cf. J. Maritain, Lecciones fundamentales de filosofía moral. Club de Lectores. Buenos Aires, 1966. 
buscando ser lo que aún no es él, en el orden dinámico-existencial, ${ }^{4}$ comprometiéndose con su necesaria humanización y proyectando su propio desarrollo humano en su respectivo contexto histórico-cultural. De este modo, la persona se aproxima a una primera forma de respuesta efectiva a la única vocación que le viene de Dios ya que, como hemos dicho, el desarrollo humano integral no sólo incluye el plano inmanente sino también el trascendente.

La vocación a la autorrealización tiene su origen en aquel Dios que es, al mismo tiempo, el fin último de todo ser humano. Efectivamente, "el desarrollo humano integral en el plano natural, al ser la respuesta a una vocación de Dios creador, requiere su autentificación en 'un humanismo trascendental, que da al hombre su mayor plenitud; ésta es la finalidad suprema del desarrollo personal. Por tanto la vocación cristiana a dicho desarrollo abarca tanto el plano natural como el sobrenatural" (CV 18). Se trata de dos planos de la respuesta vocacional personal que se orientan a un único fin trascendente que define la unidad y el sentido de la vida humana. Tales planos son distintos pero complementarios, y no se les puede asociar con dos finalidades últimas sino con una sola y única finalidad sobrenatural, Dios mismo. En realidad, "no hay más que un humanismo verdadero que se abre al Absoluto en el reconocimiento de una vocación que da la idea verdadera de la vida humana" (CV 16), teniendo en cuenta que "cada uno encuentra su propio bien asumiendo el proyecto que Dios tiene sobre él, para realizarlo plenamente: en efecto, -el hombre- encuentra en dicho proyecto su verdad $\mathrm{y}$, aceptando esta verdad, se hace libre (cf. In 8, 22)" (CV 1). Así, "en los designios de Dios, cada hombre está llamado a promover su propio progreso, porque la vida de todo hombre es una vocación" (CV 16).

\section{Apertura trascendente y relación dialógica}

La posibilidad de responder a esta vocación existencial se funda en la capacidad de apertura y de relación intersubjetiva, pues "el ser humano no es un átomo perdido en un universo casual, sino una criatura de Dios, a quien Él ha querido dar un alma inmortal y al que ha amado desde siempre" (CV 29). Es decir, "en cuanto de naturaleza espiritual, se realiza en las relaciones interpersonales... El hombre se valoriza no aislándose sino poniéndose en relación con los otros y con Dios. Por tanto, la importancia de dichas relaciones es fundamental" (CV 53). Esta capacidad de apertura y de relación de la persona no es un accidente o un sobreañadido extrínseco, sino un elemento constitutivo de su propia naturaleza, que le ha sido comunicada por Dios, pues nadie se comunica el ser a sí mismo. ${ }^{5}$ Por ello, la persona humana, desde su ser en

4 Tanto el orden dinámico-existencial como el orden ontológico son dos dimensiones distintas de una misma realidad: la persona humana. Por eso estos dos órdenes o dimensiones se complementan y se reclaman mutuamente. En el orden dinámico-existencial, la persona humana se comprende desde la fenomenología, donde el yo personal debe 'realizarse' y concretarse, pues aparece indeterminado en su origen, y en el orden ontológico o de su ser íntimo, la persona es reconocida desde la metafísica, donde su identidad individual está asegurada por el principio de individuación. Así, se reconoce a la persona humana en su ser íntimo u ontológico a través de su obrar, el cual puede ser descrito mediante la fenomenología. En este sentido, como dice K. Wojtyla: "La acción revela a la persona y miramos a la persona a través de su acción". Cf. Persona y acción, BAC, Madrid, 1982. Cf. J. A. García, Antropología Filosófica. Una introducción a la filosofía del hombre. EUNSA, España, 2001.

5 La naturaleza de la persona humana no es fija o estática sino dinámica; es principio de actividad de sus propias operaciones: el intelecto y la voluntad. Esa tiene un sentido teleológico por el que busca la realización de las potencialidades inscritas en ella misma. Por ello se dice que naturaleza y libertad se implican mutuamente y se reclaman necesariamente, de tal manera que el modo 'natural' de ser del 
sí mismo, se determina existencialmente a través de sus acciones libremente asumidas y se abre no sólo a Dios, con quien busca establecer una relación fundante, sino también a las demás personas con quienes aprende a establecer relaciones creativas y responsables.

En este sentido se afirma un personalismo social cristiano ${ }^{6}$ que logra superar las barreras antipersonalistas del colectivismo alienador, que anula la legítima autonomía y libertad de la persona humana; y del individualismo narcisista, que desconoce al otro culturalmente distinto, y niega los vínculos solidarios con graves consecuencias éticas para la vida en sociedad. La relación con los demás o con-vivencia en el bien moral, es el medio indispensable para que la persona pueda alcanzar su verdadero desarrollo humano. Por ello, cuando en la práctica social se desconoce esta dimensión constitutiva de la persona se la deshumaniza, encerrándola en sí misma y afectando gravemente la intersubjetividad dialógica que es propulsora de diversas formas creativas de cooperación, participación y reconocimiento intercultural. En este sentido, con Benedicto XVI reconocemos en el proceso de globalización, una humanidad cada vez más interrelacionada que exige la lógica del don que va más allá de la lógica económica y política, donde los individuos y la colectividad asumen sus respectivas responsabilidades. En efecto, "la verdad de la globalización como proceso y su criterio ético fundamental vienen dados por la unidad de la familia humana y su crecimiento en el bien. Por tanto, hay que esforzarse incesantemente para favorecer una orientación cultural personalista y comunitaria, abierta a la trascendencia, del proceso de integración planetaria" (CV 42). Sin embargo, se advierte también algunas dificultades y peligros que el proceso de globalización comporta, como los persistentes individualismos y utilitarismos, los cuales deben ser contrarestados viviendo y orientando la globalización de la humanidad en términos de relacionalidad, comunión y participación.

Por su parte, también la doctrina social de la Iglesia promueve este personalismo social o comunitario, tal como lo manifiesta la Constitución Pastoral Gaudium et Spes del Concilio Vaticano II cuando afirma que "Dios no creó al hombre en solitario. Desde el principio los hizo hombre y mujer (Gén 1, 27). Esta sociedad de hombre y mujer es la expresión primera de la comunión de personas humanas. El hombre es, en efecto, por su íntima naturaleza, un ser social y no puede vivir ni desplegar sus cualidades sin relacionarse con los demás" (GS 12).

Al estar insertado en la comunidad, -y en el cosmos-, el hombre requiere de la solidaridad de los otros y, por ende, de aquellas instituciones que le ayuden a responder libremente a su vocación trascendente. Por eso, Benedicto XVI considera inconcebible que los Estados gubernamentales no generen óptimas condiciones para que el hombre pueda alcanzar su fin primordial. En efecto, "cuando el Estado promueve, enseña, o incluso impone formas de ateísmo prác-

hombre es ser libre, al tiempo que la libertad es siempre según su naturaleza humana. Así, la libertad no es simplemente la facultad de hacer lo que uno quiere, sino la facultad de realizarse de acuerdo con la propia naturaleza y llevarla a plenitud. "La naturaleza del hombre es precisamente el despliegue de su ser hasta alcanzar ese bien final que constituye su perfección". Cf. J. A. García, Op.cit. EUNSA, España, 2001 .

6 La dimensión relacional de la persona humana encuentra su modelo decisivo en la relación entre las Personas de la Trinidad que se da en la única Sustancia divina. La Trinidad es absoluta unidad, en cuanto las tres Personas divinas son relacionalidad pura..., pues a la luz del misterio revelado de la Trinidad, se comprende que la verdadera apertura no significa dispersión centrífuga, sino compenetración profunda" (CV 54). 
tico, priva a sus ciudadanos de la fuerza moral y espiritual indispensables para comprometerse en el desarrollo humano integral y les impide avanzar con renovado dinamismo en su compromiso a favor de una respuesta humana más generosa al amor divino" (CV 29). En realidad, "el hombre no es capaz de gobernar por sí mismo su propio progreso, porque él solo no puede fundar un verdadero humanismo. Sólo si pensamos que se nos ha llamado individualmente y como comunidad a formar parte de la familia de Dios como hijos suyos, seremos capaces de forjar un pensamiento nuevo y sacar nuevas energías al servicio de un humanismo íntegro y verdadero" (CV 78). Pero como bien se ha dicho, "la comunidad de los hombres no absorbe en sí a la persona anulando su autonomía, como ocurre con las diversas formas del totalitarismo, sino que la valoriza más aún porque la relación entre persona y comunidad es la de un todo hacia otro todo" (CV 53).

En suma, cuando se niega la trascendencia humana y su respectiva sociabilidad, se impacta negativamente las relaciones creativas y responsables con los demás y con el medio ambiente, y se desvirtúa el sentido de la unidad de la existencia humana. Si el hombre no busca su desarrollo humano integral como bien propio entonces queda expuesto a la manipulación y frustración existencial; termina reducido en un simple "tener más", desde el que se arroja a buscar seguridades solamente en los bienes materiales inmediatos, útiles o placenteros que lo llevan a agudizar su vacío existencial y a sumergirse en devastadoras experiencias de vértigo deshumanizante, negándole a su afectividad todo su alcance y su sentido. De ahí que el Papa teólogo, después de referirse a mesianismos prometedores, pero forjados de ilusiones que basan siempre sus propuestas en la negación de la dimensión trascendente del desarrollo humano, seguros de tenerlo todo a su disposición, afirma que "esta falsa seguridad se convierte en debilidad, porque compor ta el sometimiento del hombre, reducido a un medio para el desarrollo, mientras que la humildad de quien acoge una vocación se transforma en verdadera autonomía porque hace libre a la persona" (CV 17). Propiamente, en el campo de la bioética se da una tensión entre el absolutismo de la técnica y la responsabilidad moral, y en el que está en juego la posibilidad de un desarrollo humano integral. Este es un ámbito muy delicado y decisivo, donde se plantea con toda su fuerza dramática la cuestión fundamental: si el hombre es un producto de sí mismo o si depende de Dios. Se impone la elección entre estos dos tipos de razón: una razón abierta a la trascendencia o una razón encerrada en la inmanencia. Pero la racionalidad del quehacer técnico centrada sólo en sí misma se revela como irracional, porque comporta un rechazo firme del sentido y del valor (CV 74).

\section{De la libertad de elección a la liber- tad de autodeterminación}

Otro presupuesto antropológico a considerar, es que el desarrollo humano integral exige la libertad del hombre, ya que esta parece tocar el núcleo de la persona de modo más decisivo que el del intelecto. Por su libertad constitutiva, el ser humano perfecciona lo específicamente suyo, que son sus capacidades superiores, como el entendimiento (que se orienta a la verdad) y la voluntad (que se orienta al bien) y por los que a su vez muestra su capacidad de apertura a la multiplicidad de lo real con una gran amplitud de posibilidades. Por ello, lo específico en el hombre es desarrollarse en la verdad y en el bien, a los que tiende su naturaleza dinámica. Pero el modo concreto de alcanzar tal desarrollo no está asegurado mecánicamente, ya que el hombre puede 
ir en contra de sí mismo pudiendo elegir, si quiere o no, el objeto y los medios que le corresponden, ya que ningún objeto le obliga a actuar, pues se da una independencia respecto de ello. En realidad, el hombre es libre porque puede elegir de entre todas las posibilidades que se le presentan para poder realizarse, pero deja de serlo cuando no puede elegir. Sin embargo, la libertad va más allá de la apertura trascendente y de la elección concreta, pues es también autodeterminación de la persona a través de sus acciones. La libertad es ante todo la capacidad que tiene la persona de disponer de sí misma y decidir su propio destino a través de sus acciones concretas, los cuales definen su propio modo de ser modificándose a sí misma. La persona es libre por su autodominio o autoposesión, ya que depende de sí misma, y depende de sí misma porque se autoposee. ${ }^{7}$ Así, la libertad es una propiedad de la voluntad en virtud de la cual ésta se autodetermina hacia algo que la inteligencia le presenta como bueno. Por eso se sostiene que lo propio de la libertad es la autodeterminación hacia fines. Sin embargo, esta libertad no es pura indeterminación o mera autonomía de la voluntad, ya que la voluntad siempre hace referencia al bien moral relacional presentado como tal por el intelecto y que busca elevar la acción del hombre hacia una meta superior. Asumir este significado puede ayudarnos a ser responsables con nuestra vocación a la autorrealización integral. En este sentido se entiende que Benedicto XVI sostenga que "el desarrolo humano integral supone la libertad responsable de la persona y los pueblos: ninguna estructura puede garantizar dicho desarrollo desde fuera y por encima de la responsabilidad humana, pues sólo si es libre la persona, entonces el desarrollo puede ser integralmente humano" (CV 17).

En suma, el desarrollo humano, personal y social, implica una elección radical: por o contra tal desarrollo. No se trata de elegir un simple objeto o una realidad abstracta, sino algo más profundo: la decisión sobre la unidad y el sentido de la vida. Por ello, cualquier medio o acción que realicemos, junto a otros, irá modificando nuestra identidad, es decir, nos irá configurando en nuestra personalidad $\mathrm{y}$ en nuestro proyecto vital, teniendo en cuenta, sin embargo, que optar por el desarrollo humano integral, como el criterio ético decisivo en nuestra toma de decisiones, exige también estar dispuestos a asumir los respectivos sacrificios y las ineludibles dificultades del día a día. Es decir, "cada uno de nosotros se hace por propia decisión... y somos en cierta forma nuestros propios padres, puesto que nos hacemos a nosotros tal cual deseamos" (San Gregorio de Nisa - Vita Moysis).

\section{A Modo de Conclusión: discernimiento ético y compromiso responsable}

El discernimiento ético no es un tema periférico o marginal sino más bien decisivo para lograr el desarrollo humano integral, pues las acciones que nos autodeterminan exigen ser reflexionadas y deliberadas críticamente. Por ello se busca generar criterios éticos internos que orienten la vida del hombre no sólo en la diversidad de sistemas morales y axiológicos existentes, sino también, en la toma de decisiones que configuran el propio proceso pedagógico de autorrealización existencial. Tal discernimiento, que incluye también la dimensión afectiva de las mo-

7 "En abstracto, la libertad es independencia, falta de dependencia. Pero, al contrario, la falta de dependencia del 'yo' en la dinamización de un sujeto concreto equivale a la falta de libertad, a la falta de su fundamento real" Es decir, la libertad de autodeterminación consiste en la dependencia de sí. Ver. Karol Wojtyla, Persona y acción. BAC, Madrid, 1982 
tivaciones, exige que la persona someta a revisión sus propias valoraciones morales buscando ir más allá de los costumbrismos, moralismos o legalismos de la cultura dominante que tratan de oscurecer la luz del Amor (Ágape) y de la Verdad (Logos). Al respecto, reflexionando sobre el aporte de las religiones y las culturas al desarrollo humano integral, Benedicto XVI plantea que es necesario el discernimiento sobre tal aportación, pues se debe construir la comunidad social en el respeto del bien común. Más aún sostiene que "el discernimiento deberá basarse en el criterio de la caridad y la verdad" (CV 55). Sin embargo, el mismo Papa reconoce al inicio de su encíclica que la caridad y la verdad, -en cuanto valores humanos y cristianos-, han sido desvirtuados, mal entendidos y afectados en su unidad por un relativismo -ético y filosófico- que les ha quitado su sentido, los ha excluido de la ética vivida y los ha considerado irrelevantes para la responsabilidad moral (CV 2).

De ahí la urgencia de un auténtico discernimiento ético que no puede realizarse sólo de modo individual sino, ante todo, de manera relacional, en diálogo o interacción comunicativa con, en y desde la comunidad buscando fortalecer lo que se muestra como verdadero y bueno en la concreción de las situaciones históricas que nosotros mismos construimos. En este sentido, hay que tener en cuenta lo que el mismo San Pablo aconseja a la comunidad cristiana: "No sean irreflexivos, traten de comprender lo que Dios quiere" (Ef 5, 17). En realidad, la comunidad es el espacio privilegiado para madurar y realizar un buen discernimiento en la medida que tanto la persona como la comunidad se auto-cuestionen, según las mociones del Espíritu, y revisen su propio entorno sociocultural que no siempre promueve un verdadero desarrollo humano. Sin embargo, como señala Dussel ${ }^{8}$ "no se puede negar el riesgo de un subjetivismo engañoso $y$ autosuficiente para acomodar la voluntad de Dios a la nuestra y guiar la conducta en función de nuestros propios intereses. Todos tenemos experiencias constantes de nuestra falta de objetividad, que hacen ver las mismas cosas con perspectivas muy diferentes... El sujeto que discierne no es un absoluto incondicionado, sino que se encuentra ya con una serie de influencias, que escapan de ordinario a su voluntad". Por tanto, el peligro de una deformación del discernimiento ético que afecte a nuestro desarrollo humano integral es fácil y comprensible. Por ello es necesario una profunda transformación interior o conversión del pensamiento, del corazón y de la acción, con su respectiva proyección social, cultural y ecológica. Y es precisamente aquí donde se experimenta toda la fuerza espiritual del Amor (Ágape) y de la Verdad (Palabra o Lógos), que transforma y renueva desde dentro, la propia conciencia moral, llevándola a descubrir aquello que es verdadero, bueno y agradable a los ojos de Dios.

Finalmente, este discernimiento ético no sólo se deduce como auténtico por los sentimientos de gozo, paz y alegría, sino que requiere también una verificación en la vida práctica, mediante un compromiso responsable a favor de la Justicia y la Solidaridad que es la concreción de la caridad. Toda experiencia subjetiva, si se da en sintonía con el Amor Ágape y el Lógos divino se convierte en fruto del Espíritu que guía en el bien y la verdad. "Por sus frutos los conocerán" (Mt 7,16). Como señala Pikaza9, "la ortopraxis aparece así como garantía y verificación de la autenticidad en el discernimiento". Por eso concuerdo con J. M. Castillo, cuando afirma que el

8 E. Dussel. Discernimiento: ¿Cuestión de ortodoxia u ortopraxis?, en Revista "Concilium", n 139 (1978).

9 J. Pikaza. El discernimiento de espíritu en el Nuevo Testamento, en Revista "ViRel", nº 38 (1975). 
discernimiento no es el resultado de una emotividad superficial orientada en tal o cual sentido. Ni tampoco se deduce del raciocinio y del discurso lógico sin más. El discernimiento brota de lo más profundo de nosotros mismos, es decir, de esta misteriosa profundidad del hombre de la que surgen nuestras opciones fundamentales y que implica, al mismo tiempo y en un mismo acto, idea y decisión, inclinación y connaturalidad, atracción y prontitud... Por consiguiente, el discernimiento cristiano sólo se puede realizar a partir de una renovación y de una transformación. Pero teniendo muy en cuenta que no se trata simplemente de renovar actos de la persona, sino de renovar a la persona misma, sus facultades profundas, su interioridad, su capacidad de valorar, de sentir, de enjuiciar y de amar.

\section{REFERENCIAS}

AA. W. (2006) Buscando un sentido a la vida. Lima, Instituto de Fe y Cultura UARM.

Boff, L. (2004) Ética y Moral. La búsqueda de los fundamentos. Santander, Sal Terrae.

Buber, M. (1970) Yo y tú. Buenos Aires, Ediciones Nueva Visión.

Burgos, J. M. (2003) Antropología: una guía para la existencia. Madrid, Palabra.

Frankl, V. (1999). El hombre en busca de sentido último. Barcelona, Paidós.
García Cuadrado, J. A. (2001). Antropología Filosófica. Pamplona, EUNSA.

Grisez, G. (1992) Ser Persona. Curso de Ética. Madrid, Trotta.

Küng, H. (1992) Proyecto de una ética mundial. Madrid, Trotta.

López. E. (2003) Hacia una nueva visión de la ética cristiana. Santander, Sal Terrae.

López Quintás, A. (1999) Inteligencia creativa. El descubrimiento personal de los valores. Madrid, BAC.

Mauri, M. (1987). La búsqueda del Bien. Barcelona, CASALS.

Mifsud, T. (2001). Moral Social. Lectura solidaria del continente. Bogotá, CELAM.

Mounier, E. (1997) El Personalismo. Madrid, Acción Cultural Cristiana.

Rojas, E. (1997) El Amor Inteligente. Corazón y cabeza. Madrid, Ed. Temas de Hoy.

Wojtyla, K. (1982). Persona y acción. Madrid, BAC.

Wojtyla, K. (1998) Mi visión del hombre. Hacia una nueva ética. Madrid, Palabra.

Yepes, R. (1996) Fundamentos de antropología. Un ideal de la excelencia humana. Pamplona, EUNSA.

10 J. M. Castillo, El discernimiento cristiano. Sígueme, Salamanca, 1984. 